\title{
WANITA KAWIN MEMILIH TERPISAH (MT) DALAM STATUS PERPAJAKAN DI INDONESIA
}

\author{
Rudeva Juniawaty \\ Program Studi Pendidikan Ekonomi, FIPPS \\ Universitas Indraprasta PGRI \\ Email : eva_rj@yahoo.com
}

\begin{abstract}
Can't be denied that tax is the biggest revenue source one for the state used to execute routine tasks and development. Without tax, most of the activities of the state will be difficult to implement properly. The biggest tax revenue come from income taxes and income taxes directly related to an individual taxpayer both employee and non employee are tax income article 21. One subject from the income taxes article 21 is an individual taxpayer woman. When a single woman work, usually the company where the woman works will make taxpayer identification number or the woman made by herself because she wanted to implement properly her taxation obligations. But there will be different rules when a woman has been married. By the rules a married woman who do not live alone or do not have separate property agreement, rights and obligations of taxation combined with tax obligations of her husband. Although at practice, there are many married woman who do not have a separate property agreement, but implement her own taxation obligations. Through this article the author would like to explain the tax rules that apply to a married woman and the impact if a married woman who have a taxpayer identification number which different from her husband and implement rights and obligation as a taxpayer herself.
\end{abstract}

Keywords : Tax Income Article 21, Individual Taxpayer Woman, Choose Separate

\begin{abstract}
ABSTRAK
Tidak dapat dipungkiri bahwa pajak merupakan salah satu sumber pendapatan terbesar bagi negara yang digunakan untuk menjalankan tugas rutin dan pembangunan. Tanpa pajak, sebagian besar kegiatan negara akan sulit untuk dapat dilaksanakan dengan baik. Penerimaan pajak yang terbesar salah satunya adalah Pajak Penghasilan $(\mathrm{PPh})$ dan $\mathrm{PPh}$ yang berkaitan langsung dengan WPOP baik karyawan maupun nonkaryawan adalah PPh Pasal 21. Salah satu subjek dari PPh Pasal 21 adalah WPOP wanita. Pada saat seorang wanita belum menikah (TK) bekerja, biasanya perusahaan tempat wanita tersebut bekerja akan membuatkan NPWP atau wanita tersebut membuat NPWP sendiri karena ingin melaksanakan kewajiban perpajakannya dengan baik. Namun akan menjadi berbeda aturan ketika seorang wanita telah berstatus kawin. Secara aturan wanita kawin yang tidak hidup terpisah atau tidak melakukan perjanjian pisah harta, hak dan kewajiban perpajakannya digabungkan dengan kewajiban perpajakan suaminya. Walaupun pada praktiknya, masih terdapat banyak wanita kawin yang tidak memiliki perjanjian pisah harta, namun melaksanakan kewajiban perpajakannya sendiri. Melalui artikel ini, Penulis ingin memaparkan aturan perpajakan yang berlaku bagi wanita kawin dan dampaknya jika wanita kawin tersebut memiliki NPWP yang berbeda dengan suami dan menjalankan hak dan kewajiban perpajakannya sendiri (MT).
\end{abstract}

Keywords : PPh 21, WPOP Wanita, MT (Memilih Terpisah) 


\section{PENDAHULUAN}

Ditinjau dari fungsinya, pajak memiliki salah satu fungsi, yaitu fungsi budgetair. Fungsi Budgetair adalah suatu fungsi dimana pajak digunakan sebagai alat untuk memasukkan dana secara optimal ke kas negara berdasarkan Undang - Undang yang berlaku (Pohan, 2014 : 9). Fungsi Budgetair disebut sebagai fungsi utama karena fungsi inilah yang secara historis timbul pertama kali. Berdasarkan fungsi ini pemerintah memungut dana dari penduduknya untuk membiayai berbagai kepentingan negara.

Penerimaan pajak sendiri dalam realisasi penerimaan negara tahun 2016 adalah sebesar $86,26 \%$ dari total penerimaan dalam negeri atau sebesar Rp. 1.539.166,2 Miliar (http://www.bps.go.id). Kontribusi terbesar disumbangkan dari pajak penghasilan yaitu sebesar Rp. 855.842,7 Miliar atau sebesar 55,60\% dari total penerimaan pajak. Menurut data Direktorat Jenderal Pajak (DJP), jumlah WP pada tahun 2015 mencapai 30.044.103 WP. Terdiri dari 2.472.632 WP Badan, 5.239.385 WP Orang Pribadi (OP) Nonkaryawan, dan 22.332.086 WP OP Karyawan (http://www.pajak.go.id ).

Melihat dari jumlah WPOP baik nonkaryawan maupun karyawan yang mencapai jumlah $91,77 \%$ dari total WP, penulis mencoba mengangkat salah satu materi WPOP yaitu mengenai penghitungan $\mathrm{PPh}$ terutang untuk WP wanita kawin yang memilih untuk menjalankan hak dan kewajiban perpajakannya sendiri (MT) dan implikasinya terhadap perlakuan perpajakannya.

Hal ini disebabkan oleh, dalam praktiknya masih banyak terdapat WPOP wanita yang menjalankan kewajiban perpajakannya masing-masing, tidak digabungkan dengan kewajiban perpajakan suaminya. Salah satu penyebab terjadinya hal tersebut adalah karena ketidaktahuan WPOP wanita, bahwa ketika seorang wanita telah menikah, kewajiban perpajakannya harus disatukan dengan suami. Karena pada dasarnya sistem pengenaan pajak berdasarkan Undang Undang Pajak Penghasilan No. 36 Tahun 2008, tepatnya dipenjelasan pasal 8 dinyatakan bahwa keluarga sebagai satu kesatuan ekonomis.

Berdasarkan hal tersebut, penulis mencoba membahas aturan perpajakan yang berlaku bagi wanita kawin dan dampaknya jika wanita kawin tersebut memiliki NPWP yang berbeda dengan suami dan menjalankan hak dan kewajiban perpajakannya sendiri (MT). Walaupun hal tersebut bukanlah hal yang baru terjadi, namun penulis berharap dengan artikel ini dapat membantu pemahaman lebih terhadap pengaplikasian pelaporan SPT PPh Tahunan Orang Pribadi.

\section{METODE}

Pendekatan yang digunakan dalam penelitian ini adalah pendekatan kualitatif. Berdasarkan jenis tujuan penelitian, penelitian ini adalah penelitian deskriptif. Penelitian ini menggunakan dua teknik penggumpulan data, yaitu studi kepustakaan dan studi lapangan (wawancara).

\section{HASIL DAN PEMBAHASAN}

Berikut merupakan hasil dari penelitian yang telah dilakukan yang berhubungan dengan Wanita Kawin Memilih Terpisah (MT) dalam Status Perpajakan di Indonesia :

\begin{tabular}{|c|l|l|l|l|}
\hline No & \multicolumn{1}{|c|}{ Nama } & \multicolumn{1}{|c|}{ Judul } & \multicolumn{2}{|c|}{ Metode Penelitian } \\
\hline 1. & $\begin{array}{l}\text { Susi Diah } \\
\text { Anggarsari }\end{array}$ & $\begin{array}{l}\text { Analisis Perlakuan Pajak } \\
\text { Penghasilan Bagi Wajib Pajak } \\
\text { Wanita Kawin. }\end{array}$ & $\begin{array}{l}\text { Pendekatan penelitian yang digunakan } \\
\text { adalah pendekatan kualitatif deskriptif. } \\
\text { Penelitian menggunakan dua teknik } \\
\text { penggumpulan data : studi kepustakaan dan } \\
\text { studi lapangan }\end{array}$ \\
\hline
\end{tabular}




\begin{tabular}{|c|c|c|}
\hline & Hasil & $\begin{array}{l}\text { Kekeliruan dalam perhitungan pajak penghasilan atas WP wanita kawin yang } \\
\text { memiliki hak dan kewajiban perpajakannya sendiri dapat menimbulkan } \\
\text { kerugian pada negara. Selain itu juga dapat menimbulkan sanksi perpajakan } \\
\text { bagi wanita tersebut. Adanya kekeliruan dalam perhitungan pajak penghasilan } \\
\text { terutang bagi wanita kawin tersebut dikarenakan kurangnya sosialisasi dan } \\
\text { penyuluhan dari pihak pemerintah. Upaya sosialisasi melalui media surat kabar } \\
\text { ternyata kurang mancapai sasaran. Terbukti masih banyaknya wajib pajak } \\
\text { wanita kawin yang memilih untuk menjalankan hak dan kewajiban } \\
\text { perpajakannya sendiri belum mengetahui cara menghitung pajak penghasilan } \\
\text { terutangnnya sesuai peraturan. }\end{array}$ \\
\hline \multirow[t]{2}{*}{2.} & $\begin{array}{l}\text { Titin } \\
\text { Fachriah } \\
\text { Nur }\end{array}$ & $\begin{array}{l}\text { Implementasi PER }-19 / \text { PJ/ } \\
2014 \quad \text { Penelitian bersifat kualitatif. Pengumpulan } \\
\text { Penghasilan Orang Pribadi dan } \\
\text { Kepatuhan Pajak }\end{array}$ \\
\hline & Hasil & $\begin{array}{l}\text { Pemilihan penerapan perhitungan suami istri yang dianggap memilih } \\
\text { perhitungan MT, dalam kondisi istri berpenghasilan dari satu pemberi kerja } \\
\text { namun telah memiliki NPWP dan pada saat pelaporan SPT WPOP tahun } 2014 \\
\text { belum mencabut NPWP. Dengan kondisi tersebut dapat ditarik kesimpulan } \\
\text { bahwa terdapat pengaruh peningkatan tarif karena penggabungan terhadap } \\
\text { kepatuhan Wajib Pajak. }\end{array}$ \\
\hline
\end{tabular}

\section{Subjek Pajak}

Menurut UU no. 36 Tahun 2008 Pasal 2 ayat 1 , yang menjadi subjek pajak adalah : a. 1 . orang pribadi; 2 . warisan yang belum terbagi sebagai satu kesatuan menggantikan yang berhak; b. badan; dan c. bentuk usaha tetap. (1a) Bentuk usaha tetap merupakan subjek pajak yang perlakuan perpajakannya dipersamakan dengan subjek pajak badan.

\section{Objek Pajak}

Menurut UU no. 36 Tahun 2008 Pasal 2, yang menjadi objek pajak adalah penghasilan, yaitu setiap tambahan kemampuan ekonomis yang diterima atau diperoleh WP, baik yang berasal dari Indonesia maupun dari luar Indonesia, yang dapat dipakai untuk konsumsi atau untuk menambah kekayaan WP yang bersangkutan, dengan nama dan dalam bentuk apa pun.

Setiap WP yang telah memenuhi persyaratan subjektif dan objektif sesuai dengan ketentuan peraturan perundangundangan perpajakan wajib mendaftarkan diri pada kantor Direktorat Jenderal Pajak yang wilayah kerjanya meliputi tempat tinggal atau tempat kedudukan WP dan kepadanya diberikan NPWP. Kewajiban mendaftarkan diri tersebut berlaku pula terhadap wanita kawin yang dikenai pajak secara terpisah karena hidup terpisah berdasarkan keputusan hakim atau dikehendaki secara tertulis berdasarkan perjanjian pemisahan penghasilan dan harta. Sesuai dengan Surat Edaran Direktur Jendral Pajak Nomor SE - 29/PJ/2010 Penjelasan Pasal 2 ayat (1).

Wanita kawin selain tersebut di atas dapat mendaftarkan diri untuk memperoleh NPWP atas namanya sendiri agar wanita kawin tersebut dapat melaksanakan hak dan memenuhi kewajiban perpajakannya terpisah dari hak dan kewajiban perpajakan suaminya.

Pada saat WPOP wanita dengan status tidak kawin melaporkan SPT Tahunannya, WPOP wanita tersebut dapat langsung melaporkan apa yang tertera dalam bukti potong A1 - PPh Pasal 21 ke dalam SPT Tahunan. Namun akan berbeda cara pelaporannya jika seorang WPOP wanita telah menikah. Pelaporan SPT Tahunan WPOP wanita harus digabungkan dengan SPT Tahunan suaminya. Hal ini dikarenakan dalam Undang - Undang No. 36 Tahun 2008 tentang Pajak Penghasilan Pasal 8 ayat (1) menjelaskan sebagai berikut : 
Seluruh penghasilan atau kerugian bagi wanita yang telah kawin pada awal tahun pajak atau pada awal bagian tahun pajak, begitu pula kerugiannya yang berasal dari tahun-tahun sebelumnya yang belum dikompensasikan dianggap sebagai penghasilan atau kerugian suaminya, kecuali penghasilan tersebut semata-mata diterima atau diperoleh dari 1 (satu) pemberi kerja yang telah dipotong pajak berdasarkan ketentuan Pasal 21 dan pekerjaan tersebut tidak ada hubungannya dengan usaha atau pekerjaan bebas suami atau anggota keluarga lainnya.

Sistem pengenaan Pajak Penghasilan di Indonesia menempatkan keluarga sebagai satu kesatuan ekonomis, artinya penghasilan atau kerugian dari seluruh anggota keluarga digabungkan sebagai satu kesatuan yang dikenai pajak dan pemenuhan kewajiban perpajakannya dilakukan oleh kepala keluarga. $\mathrm{PPh}$ terutang tersebut meliputi seluruh penghasilan yang diterima baik oleh suami, istri, maupun oleh anak yang belum dewasa dari manapun sumbernya dan apapun sifat pekerjaannya.

Namun demikian, dalam hal-hal tertentu mengenai pengenaan $\mathrm{PPh}$ dapat dilakukan secara terpisah antara suami dan istri bukan sebagai satu kesatuan ekonomis. Hal-hal tertentu tersebut diantaranya adalah apabila suami-istri telah hidup berpisah berdasarkan keputusan hakim, atau apabila dikehendaki secara tertulis oleh suami-istri berdasarkan perjanjian pemisahan harta dan penghasilan.

\section{Kewajiban Perpajakan Bagi Wanita yang Berstatus Kawin}

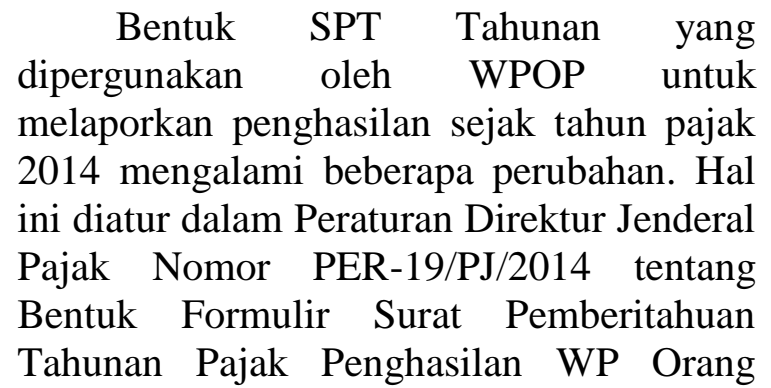

Pribadi dan WP Badan Beserta Petunjuk Pengisiannya. Perubahan tersebut adalah dengan terdapatnya kolom yang menyatakan status kewajiban perpajakan suami-istri yaitu kolom $\mathrm{KK}, \mathrm{HB}, \mathrm{PH}$, dan MT.

Pada lampiran PER-19/PJ/2014 dijelaskan maksud dari status kewajiban perpajakan tersebut adalah : 1). Status perpajakan KK (Kepala Keluarga) : kewajiban perpajakan suami-istri digabung, istri dapat menggunakan NPWP suami sebagai sarana perpajakannya. 2). Status perpajakan HB (Hidup Berpisah) : WP yang memiliki status perpajakan HB dikenai pajak secara terpisah, karena suamiistri telah hidup berpisah berdasarkan putusan Hakim. 3). Status perpajakan $\mathrm{PH}$ (Pisah Harta) : penghasilan suami-istri dikenai pajak secara terpisah karena dikehendaki secara tertulis berdasarkan perjanjianpemisahan harta dan penghasilan. 4). Status perpajakan MT (Memilih Terpisah) : penghasilan suami-istri dikenai pajak secara terpisah karena dikehendaki oleh istri yang memilih untuk menjalankan hak dan kewajiban perpajakannya sendiri.

Peraturan mengenai status kewajiban perpajakan suami-istri ini sebenarnya telah diatur sejak 2008 dan mulai berlaku sejak 1 Januari 2009 tercantum yang dalam UU No. 36 Tahun 2008 dan ditegaskan dalam SE29/PJ/2010 yaitu kewajiban mendaftarkan diri dan pemberian NPWP bagi WP yang telah terpenuhi kewajiban subyektif dan obyektifnya. Dalam SE - 29 tersebut juga dijelaskan bahwa kewajiban mendaftarkan diri tersebut berlaku pula terhadap wanita kawin yang dikenai pajak secara terpisah karena hidup terpisah berdasarkan keputusan hakim atau dikehendaki secara tertulis berdasarkan perjanjian pemisahan penghasilan dan harta. Wanita kawin selain tersebut di atas dapat mendaftarkan diri untuk memperoleh NPWP atas namanya sendiri agar wanita kawin tersebut dapat melaksanakan hak dan memenuhi kewajiban perpajakannya terpisah dari hak dan kewajiban perpajakan suaminya. 
Walaupun aturan tersebut telah berlaku lama, namun faktanya masih banyak WPOP yang tidak mengetahui mengenai peraturan ini. Sehingga WPOP wanita dengan status kawin tetap melaksanakan kewajiban perpajakannya sendiri, tetap menggunakan NPWP nya sendiri, padahal tidak terdapat perjanjian pisah harta ataupun hidup berpisah berdasarkan keputusan hakim. Pada SPT tahunan tahun pajak 2014 muncul status kewajiban perpajakan yang pada tahun tahun pajak sebelumnya, tidak terdapat kolom mengenai status kewajiban perpajakan suami-istri pada SPT 1770 dan $1770 \mathrm{~S}$.

Kesalahan dalam pemilihan status kewajiban perpajakan dapat mengakibatkan kurang/ lebih bayar PPh Pasal 21 walaupun penghasilan WPOP telah dipotong oleh pemberi kerja. Pemunculan status perpajakan dalam efilling pada SPT Tahunan WPOP diharapkan agar WPOP lebih memahami Undang - Undang Perpajakan yang berlaku di Indonesia. Mengingat sistem perpajakan di Indonesia menganut sistem self assessment, yang mewajibkan WP untuk menghitung, memperhitungkan, membayar dan melaporkan sendiri pajak atas penghasilan yang diterima. WP dituntut untuk mampu memahami dan mengetahui ketentuan perpajakan yang berlaku, paling tidak yang menyangkut tentang kewajiban dirinya atau usaha yang dimiliki. Maka jika terdapat kesalahan administrasi yang dilakukan oleh WP, dapat mengakibatkan sanksi denda dan bunga $2 \%$.

\section{PPh Pasal 21 Terutang WPOP Status KK dan MT}

Penghitungan $\mathrm{PPh}$ terutang bagi suami istri yang dikenai pajak secara terpisah, yaitu dikenakan pajak berdasarkan penggabungan penghasilan neto suami istri. Besarnya $\mathrm{PPh}$ yang harus dilunasi oleh masing-masing suami-istri dihitung secara proporsional. Hal ini sesuai dengan Undang - Undang No. 36 Tahun 2008 Pasal 8 ayat 3 disebutkan bahwa :

Penghasilan neto suami-istri sebagaimana dimaksud pada ayat (2) huruf $b$ dan huruf $c$ dikenai pajak berdasarkan penggabungan penghasilan neto suami istri dan besarnya pajak yang harus dilunasi oleh masing-masing suami-istri dihitung sesuai dengan perbandingan penghasilan neto mereka.

Akibatnya, kemungkinan akan terdapat WPOP wanita kawin yang menerima penghasilan hanya dari 1 pemberi kerja sebagai SPT Tahunan Orang Pribadi menjadi kurang bayar/ lebih bayar. Namun jika status kewajiban perpajakan suami-istri adalah $\mathrm{KK}$, penghasilan istri tersebut dianggap sebagai penghasilan yang dikenai pajak bersifat final.

Berikut contoh kasus penghitungan PPh untuk WPOP kawin yang status kewajiban perpajakannya MT. Contoh kasus : Bapak Atom status kawin mempunyai 3 orang anak, dalam tahun 2016 memperoleh penghasilan netto dari pekerjaan sebesar Rp 234.360.000,-. Istri Pak Atom menerima penghasilan netto dari pekerjaan sebesar Rp 186.060.000,Ilustrasi perhitungan sesuai tabel dibawah ini : 
Tabel 1. Perhitungan Penghasilan Kena Pajak

\begin{tabular}{|l|r|r|}
\hline \multicolumn{1}{|c|}{ Keterangan } & \multicolumn{1}{c|}{ Suami (K/3) } & \multicolumn{1}{c|}{ Isteri (TK/0) } \\
\hline Gaji & 180.000 .000 & 150.000 .000 \\
\hline Tunjangan transport & 60.000 .000 & 42.000 .000 \\
\hline JKK & 1.800 .000 & 1.500 .000 \\
\hline BPJS Kesehatan & 960.000 & 960.000 \\
\hline Penghasilan Bruto Setahun & 242.760 .000 & 194.460 .000 \\
\hline Pengurang : & & \\
\hline Biaya jabatan & 6.000 .000 & 6.000 .000 \\
\hline Iuran pensiun & 2.400 .000 & 2.400 .000 \\
\hline Total Pengurang & 8.400 .000 & 8.400 .000 \\
\hline Penghasilan Netto setahun & $\mathbf{2 3 4 . 3 6 0 . 0 0 0}$ & $\mathbf{1 8 6 . 0 6 0 . 0 0 0}$ \\
\hline PTKP (K/3) & 72.000 .000 & 54.000 .000 \\
\hline Penghasilan Kena Pajak & $\mathbf{1 6 2 . 3 6 0 . 0 0 0}$ & $\mathbf{1 3 2 . 0 6 0 . 0 0 0}$ \\
\hline
\end{tabular}

Sumber: Diolah oleh peneliti

Tabel 2. Perhitungan PPh Pasal 21 Terutang Setahun

\begin{tabular}{|c|c|c|c|}
\hline \multicolumn{4}{|c|}{ PPh Pasal 21 terutang setahun : } \\
\hline \multicolumn{2}{|c|}{ Suami $(\mathbf{K} / \mathbf{3})$} & \multicolumn{2}{|c|}{ Isteri (TK/0) } \\
\hline $5 \% \times \quad \times 0.000 .000=$ & 2.500 .000 & $5 \% \quad \times \quad 50.000 .000$ & 2.500 .000 \\
\hline $15 \% \times 112.360 .000=$ & 16.854 .000 & $15 \% \times 82.060 .000=$ & 12.309 .000 \\
\hline & 19.354.000 & & 14.809 .000 \\
\hline
\end{tabular}

Sumber : Diolah oleh Peneliti

Bapak Atom telah dipotong PPh Pasal 21 sebesar Rp. 19.354.000,-.-sedangkan istri Pak Atom telah dipotong PPh Pasal 21 sebesar Rp. 14.809.000,-.
Untuk penghitungan berdasarkan peraturan/ lembar penghitungan PPh bagi WP yang kawin dengan status perpajakan suami istri PH atau MT, dapat dilihat pada tabel dibawah ini :

Tabel 3. Perhitungan PPh WP Kawin dengan status MT

\begin{tabular}{|c|c|c|c|}
\hline \multicolumn{2}{|l|}{ Penghasilan Neto Suami } & & 234.360 .000 \\
\hline \multicolumn{2}{|l|}{ Penghasilan Neto istri } & & 186.060 .000 \\
\hline \multicolumn{2}{|l|}{ Penghasilan Neto Gabungan } & & 420.420 .000 \\
\hline \multicolumn{2}{|l|}{$\operatorname{PTKP}(\mathrm{K} / \mathrm{I} / 3)$} & & 126.000 .000 \\
\hline \multicolumn{2}{|l|}{ Penghasilan Kena Pajak } & & 294.420.000 \\
\hline \multicolumn{4}{|c|}{ PPh te rutang Gabungan (suami - is teri) : } \\
\hline \multicolumn{2}{|l|}{$5 \%$ x Rp. $50.000 .000=$} & & 2.500 .000 \\
\hline \multicolumn{2}{|l|}{$15 \%$ x Rp. 200.000 .000} & & 30.000 .000 \\
\hline \multirow{2}{*}{\multicolumn{2}{|c|}{$25 \% \times$ Rp. $44.420 .000=$}} & & 11.105 .000 \\
\hline & & & 43.605.000 \\
\hline \multicolumn{4}{|c|}{ PPh Te rutang } \\
\hline \multicolumn{4}{|l|}{ yang ditanggung suami : } \\
\hline \multicolumn{2}{|r|}{$\begin{array}{l}234.360 .000 \\
420.420 .000\end{array}$} & x 43.605.000 & $=24.307 .283$ \\
\hline \multicolumn{4}{|l|}{ yang ditanggung isteri: } \\
\hline & $\begin{array}{l}186.060 .000 \\
420.420 .000\end{array}$ & $x 43.605 .000$ & $=19.297 .717$ \\
\hline
\end{tabular}

Sumber : Diolah oleh peneliti 
Sehingga PPh Kurang/(Lebih) Bayar pada SPT Tahunan Orang Pribadi adalah sebagai berikut :

\begin{tabular}{|l|r|r|}
\hline \multicolumn{1}{|c|}{ Keterangan } & \multicolumn{1}{c|}{ SPT Suami } & \multicolumn{1}{c|}{ SPT Isteri } \\
\hline PPh Terutang & 24.307 .283 & 19.297 .717 \\
\hline Kredit Pajak - PPh 21 & 19.354 .000 & 14.809 .000 \\
\hline PPh Kurang/ (Lebih) Bayar & 4.953 .283 & 4.488 .717 \\
\hline
\end{tabular}

Sumber : Diolah oleh peneliti

\section{Dampak Status Perpajakan MT}

Dari contoh kasus diatas, WPOP yang seharusnya SPT Tahunannya Nihil, menjadi kurang bayar. Akibat dari kurang bayar tersebut adalah terdapat WP yang mau melunasi utang pajaknya, namun tidak sedikit pula yang mengabaikan kurang bayar tersebut karena menganggap $\mathrm{PPh}$ Pasal 21 telah dipotong oleh pemberi kerja.

Namun dalam SPT Tahunan yang dilaporkan melalui efilling jika memilih status KK dengan NPWP yang berbeda maka akan terjadi kurang/ lebih bayar yang harus dilunasi terlebih dahulu sebelum SPT Tahunan tersebut dapat dikirim dan dilaporkan secara online kepada Direktorat Jendral Pajak. Apabila WP tidak ingin melunasi utang pajaknya, maka WPOP harus memilih status MT pada form efilling tersebut. Sedangkan pemilihan status MT secara Undang - Undang yang berlaku di Indonesia tidak diperbolehkan kecuali telah ada perjanjian pisah harta ataupun hidup berpisah dengan keputasan hakim. Jika tidak ada keduanya, maka mutlak WPOP harus memilih status KK.

Ada pula WPOP yang patuh karena tidak ingin mendapat sanksi denda maupun bunga maka WPOP tersebut melunasi utang pajaknya segera, walaupun WPOP tidak mengetahui adanya ketentuan seperti itu. Hal ini berdampak baik kepada penerimaan Negara karena semakin bertambah. Namun di sisi lain, ada pula WPOP yang tidak mau membayar kekurangan utang pajaknya, salah satunya mungkin dikarenakan utang pajak yang masih harus dilunasi cukup besar.

Akibat dari penghindaran pembayaran utang pajak dengan memilih status MT, mengakibatkan kepatuhan WP berkurang. Pemilihan status MT pun bukan semata untuk menghindari utang PPh Pasal 21, namun karena ketidaktahuan WPOP. Karena kebanyakan WPOP beranggapan bahwa kewajibannya telah tuntas karena PPh Pasal 21 - nya telah dipotong dari gaji. Bagi WP yang tidak memahami ketentuan perpajakan yang berlaku, perhitungan pajak secara proporsional itu dianggap tidak adil bagi mereka karena seolah - olah penghasilan terpotong 2 kali. Namun karena secara Undang - Undang Pajak Penghasilan menjelaskan bahwa keluarga sebagai satu kesatuan ekonomis, maka setiap WP harus tunduk pada Undang Undang yang berlaku karena hukum Undang - Undang tersebut mengikat.

Namun jika WP dengan sengaja menyampaikan SPT tetapi isinya tidak benar atau tidak lengkap atau melampirkan keterangan yang isinya tidak benar, sehingga dapat menimbulkan kerugian pada pendapatan Negara dan perbuatan tersebut merupakan perbuatan setelah perbuatan yang pertama kali sebagaimana dimaksud dalam Pasal 13A, didenda paling sedikit 1 (satu) kali jumlah pajak terutang yang tidak atau kurang dibayar dan paling banyak 2 (dua) kali jumlah pajak terutang yang tidak atau kurang dibayar, atau dipidana kurungan paling singkat 3 (tiga) bulan atau paling lama 1 (satu) tahun. (Undang Undang No. 28 Tahun 2007 tentang Ketentuan Umum dan Tata Cara Perpajakan Pasal 38 (b). 


\section{SIMPULAN DAN SARAN}

\section{Simpulan}

1. Berdasarkan penelitian terdahulu tidak ada perubahan apabila WPOP wanita yang memiliki NPWP yang berbeda dengan suami dan menjalankan hak serta kewajiban perpajakannya sendiri (MT). Antara lain yaitu :

a. Kurang bayar menjadi salah satu dampak bagi wanita kawin yang memiliki NPWP yang berbeda dengan suami dan menjalankan hak serta kewajiban perpajakannya sendiri (MT).

b. WPOP akan melakukan pelanggaran Undang - Undang Pajak Penghasilan, yang dapat mengakibatkan sanksi denda dan bunga.

2. Jika WP dengan sengaja menyampaikan SPT tetapi isinya tidak benar atau tidak lengkap atau melampirkan keterangan yang isinya tidak benar, sehingga dapat menimbulkan kerugian pada pendapatan negara dan perbuatan tersebut merupakan perbuatan setelah perbuatan yang pertama kali, didenda paling sedikit 1 (satu) kali jumlah pajak terutang yang tidak atau kurang dibayar dan paling banyak 2 (dua) kali jumlah pajak terutang yang tidak atau kurang dibayar, atau dipidana kurungan paling singkat 3 (tiga) bulan atau paling lama 1 (satu) tahun.

3. Status kewajiban perpajakan suami-istri memilih terpisah (MT) adalah status kewajiban perpajakan dimana suami-istri menghendaki untuk menjalankan hak dan kewajiban perpajakannya secara terpisah. Apabila status kewajiban perpajakan suami-istri memililh terpisah (MT), penghitungan $\mathrm{PPh}$ terutang untuk suami dan istri dihitung berdasarkan perbandingan penghasilan neto mereka. WPOP yang berstatus perpajakan memilih terpisah (MT) disebabkan karena beberapa hal. Yang dominan menyebabkan hal ini adalah kekurangtahuan WPOP mengenai peraturan perpajakan.

\section{Saran}

1. WPOP harus lebih memahami peraturan perpajakan yang berlaku, karena sistem self assessment yang mengharuskan WPOP memahami peraturan perpajakan yang terkait dengan dirinya ataupun usaha yang dimilikinya.

2. WPOP wanita kawin (yang memperoleh penghasilan semata-mata dari satu pemberi kerja) yang memiliki NPWP berbeda dengan suami tanpa adanya perjanjian pisah harta harus segera menutup NPWP nya.dan membuat NPWP yang sama dengan suami.

3. Sebelum menutup NPWP, WPOP wanita kawin harus terlebih dahulu menyelesaikan semua kewajiban perpajakan yang belum dilakukan. Untuk pelaporan SPT Tahunan istri, digabung dengan SPT Tahunan suami, sehingga penghasilan yang diterimanya dari satu pemberi kerja tersebut, dianggap sebagai penghasilan yang bersifat final pada SPT Tahunan suami.

4. Melakukan pembetulan SPT Tahunan, yang sebelumnya tidak menggunakan teknis penghitungan $\mathrm{PPh}$ yang dihitung sesuai dengan perbandingan penghasilan neto mereka, maka pada pembetulan SPT Tahunan menggunakan teknis penghitungan sesuai dengan perbandingan penghasilan neto. Apabila SPT Tahunannya menjadi kurang bayar, maka atas kurang bayar tersebut harus segera dilunasi.

\section{DAFTAR PUSTAKA}

Mardiasmo.(2016).Perpajakan Edisi Terbaru. Yogyakarta:ANDI Yogyakarta.

Ortax Training Center.(2016).Modul Training Updating PPh 21 : Pahami Teknis Penanganan Lebih Bayar Akibat Perubahan PTKP, Jakarta, Ortax

Pohan,C.A.(2014),Pembahasan

Komprehensif Perpajakan Indonesia 
Teori dan Kasus, Jakarta, Mitra Wacana Media

Priantara, D.(2012).Perpajakan Indonesia Edisi 2,Jakarta, Mitra Wacana Media

Belianto, D.(2016).Milih Pisah, Jakarta, Ortax Bulletin Edisi Perdana Maret 2016.

Undang-undang Republik Indonesia Nomor 36 Tahun 2008 Tentang Perubahan Keempat Atas Undang-Undang No. 7 Tahun 2008 Tentang Pajak Penghasilan

Undang-Undang No. 7 Tahun 1983 tentang Pajak Penghasilan (Lembaran Negara Republik Indonesia Tahun 2008 Nomor 133).

Undang-Undang No. 28 Tahun 2007 Tentang Ketentuan Umum dan Tata Cara Perpajakan

Peraturan Pemerintah Nomor 74 Tahun 2011 Tentang Tata Cara Pelaksanaan Hak dan Pemenuhan Kewajiban Perpajakan.

Peraturan Menteri Keuangan Nomor 17/PMK.03/2013 tentang Tata Cara Pemeriksaan.

Peraturan Direktur Jenderal Pajak Nomor PER-19/PJ/2014 Tentang Perubahan Kedua atas Peraturan Direktur Jenderal Pajak Nomor PER34/PJ/2010 tentang Bentuk Formulir Surat Pemberitahuan Tahunan Pajak Penghasilan WP Orang Pribadi dan WP Badan Beserta Petunjuk Pengisiannya.

Surat Edaran Direktur Jenderal Pajak Nomor SE-29/PJ/2010 Tentang Pengisian Surat Pemberitahuan Tahunan Pajak Penghasilan WP
Orang Pribadi Bagi anita Kawin yang melakukan perjanjian pemisahan harta dan penghasilan atau yang memilih untuk menjalankan Hak dan Kewajibannya sendiri.

Pemeriksapajak.com (2015), Perlakuan Pajak Bagi Wanita Kawin, https://pemeriksaanpajak.com/2015/1 0/26/perlakuan-pajak-bagi-wanitakawin/ . Diakses pada tanggal 28 Januari 2017

Anggrainy (2016), Perlukah Istri Yang Bekerja Memiliki NPWP Sendiri?, http://www.pajak.go.id/content/article /perlukah-istri-yang-bekerjamemiliki-npwp-sendiri. Diakses pada tanggal 28 Januari 2017

Realisasi Penerimaan Negara (Milyar Rupiah), $2007 \quad-\quad 2017$ https://www.bps.go.id/index.php/link TabelStatis/1286. Diakses pada tanggal 29 Januari 2017

Arifin, Gusfahmi (2016), Perlunya Reformasi Pajak (http://www.pajak.go.id/content/articl e/perlunya-reformasi-pajak Diakses pada tanggal 29 Januari 2017

Anggarsari, Susi Diah. (2010) Analisis Perlakuan Pajak Penghasilan Bagi Wajib Pajak Wanita Kawin. Jurnal Ilmu Administrasi dan Organisasi, Volume 17 Nomor 2, Mei - Agustus 2010, ISSN 0854 - 3844

Nur, Titin Fachriah. (2014). Implementasi PER - 19/ PJ/ 2014 Terhadap Tarif Penghasilan Orang Pribadi dan Kepatuhan Pajak. Jurnal Vokasi Indonesia, Volume 2 Nomor 2 Juli Desember 2014, ISSN 2355 - 5807 